ENVIRONMENTAL EXPOSURE

\title{
Effects of asbestos and smoking on the levels and rates of change of lung function in a crocidolite exposed cohort in Western Australia
}

\author{
H S Alfonso, L Fritschi, N H de Klerk, N Olsen, J Sleith, A W Musk
}

Thorax 2004;59:1052-1056. doi: 10.1136/thx.2004.022806

See end of article for authors' affiliations

......................

Correspondence to: Dr H S Alfonso, School of Public Health, Curtin University of Technology, GPD Box U1987, Perth,

Western Australia,

Australia;

h.alfonso@curtin.edu.au

Received 4 February 2004 Accepted

13 September 2004
Background: Increased rates of death from asbestos related diseases have been reported in former workers and residents exposed to crocidolite (blue asbestos) at Wittenoom, Western Australia. Exposure to asbestos is associated with reduced static lung volumes, gas transfer and lung compliance, and a restrictive ventilatory abnormality.

Methods: The effects of crocidolite exposure and smoking history on levels and rates of change of lung function were evaluated using a linear mixed model. Lung function was measured as forced expiratory volume in 1 second $\left(F E V_{1}\right)$, forced vital capacity (FVC), and $F E V_{1} / F V C$.

Results: Cumulative doses of asbestos and the presence of radiographic asbestosis were associated with lower levels of $\mathrm{FEV}_{1}$ and FVC and a steeper decline during the period of observation. Subjects exposed to asbestos at a younger age had lower levels of FEV 1 and FVC. Current smokers had lower levels and a steeper decline in lung function than never smokers. No significant interactions between crocidolite exposure and smoking on the levels or rates of change of lung function were found.

Conclusions: The deleterious effects of crocidolite exposure on lung function persist in this population, despite asbestos exposure having ceased more than 30 years ago. No significant interactions were found in this population between asbestos and smoking at the first visit or longitudinally.
$\mathrm{E}$ xposure to asbestos is a well recognised cause of interstitial lung disease (asbestosis), a condition characterised by reduced static lung volumes, gas transfer and lung compliance, and a restrictive ventilatory abnormality. ${ }^{1}$ Cross sectional and longitudinal studies have shown that greater intensity and duration of asbestos exposure are associated with a greater decline in pulmonary function. ${ }^{23}$ Cigarette smoking is the main cause of chronic obstructive pulmonary disease, particularly emphysema. It has been proposed that smoking enhances the development of interstitial fibrosis in workers exposed to asbestos. ${ }^{45}$

Blue asbestos (crocidolite) was mined at Wittenoom, Western Australia, by the Australian Blue Asbestos Company (ABA) from 1943 until 1966. ${ }^{6}$ During the period of operation of the industry approximately 7000 workers were employed in the mining and milling operations and about 5000 people lived in the nearby town but did not work in the asbestos production processes. ${ }^{78}$ The people employed in the industry and those living in the town with environmental exposure to crocidolite have been shown to be at increased risk of developing both asbestos and smoking related diseases. ${ }^{6}$ The Wittenoom cohorts are unique in being the only well documented cohorts in the world who have had almost exclusive exposure to known quantities of the crocidolite form of asbestos. In an attempt to reduce the occurrence of malignant mesothelioma and lung cancer in former workers and residents from Wittenoom, an intervention was established in 1990 using supplemental vitamin A as retinol or $\beta$-carotene until September 1997, ${ }^{90}$ and since then as retinol only. All subjects have been seen annually and have been given advice on smoking, diet and exercise, and offered assistance to stop smoking.

The aim of this analysis was to examine the effects of crocidolite exposure and smoking on the levels and rates of change of lung function (measured as forced expiratory volume in 1 second $\left(\mathrm{FEV}_{1}\right)$, forced vital capacity (FVC), and $\mathrm{FEV}_{\mathrm{l}} / \mathrm{FVC}$ ), after adjusting for potential confounders.

\section{METHODS \\ Subjects}

Follow up on cohorts of former workers and residents of Wittenoom have been maintained since 1979. Ex-residents or ex-workers who could be located were invited to participate in the Vitamin A Program, and the Program has continued accepting participants over time. Although the Vitamin A Program was established in 1990, annual spirometric measurements did not start until 1992. This study included all people who have participated in the Vitamin A Program with at least one measurement of $\mathrm{FEV}_{1}$ and FVC. The follow up started at the first spirometric test available, and participants were followed up to the last spirometric test available before 23 September 2002. People aged under 25 years at entry into the Program were excluded because lung growth may continue to this age. ${ }^{11}$

All subjects gave their informed consent and the study was approved by the human research ethics committee of the University of Western Australia and the Clinical Drug Trials Committee of the Sir Charles Gairdner Hospital, Nedlands, Western Australia.

\section{Pulmonary function testing}

$\mathrm{FEV}_{1}$ and FVC measurements were performed by trained technicians according to the guidelines of the American Thoracic Society (ATS) ${ }^{12}$ and adjusted for body temperature and pressure saturated with water vapour. Measurements in which the two highest attempts fulfilled the ATS criteria for reproducibility (an agreement within 5\%) were included in the analysis.

A Vitalograph dry bellows spirometer (Vitalograph Ltd, Buckingham, UK) was used from 1992 until November 1998, 
and then only occasionally; a Medical Graphics 1070 system (Medical Graphics, St Paul, MN, USA) has been used since November 1998. The calibration of the spirometers was checked daily, their reliability was assessed monthly, and maintenance and servicing was regularly undertaken.

\section{Asbestos exposure assessment}

Methods describing the detailed assessment of crocidolite exposure for workers have been described previously: ${ }^{7}$ job histories were obtained from employment records; fibre concentrations for all job categories were estimated from the results of a survey of airborne respirable fibres of crocidolite that was carried out at various work sites at Wittenoom in 1966 and particle counts performed by the Mines Department of Western Australia during the life of the industry. Each subject's cumulative exposure was calculated by adding over all their different jobs the product of estimated or measured fibre concentration and the length of time in that job.

For ex-residents, the estimation of individual asbestos exposure levels has also been described in detail elsewhere. ${ }^{8}$ Using data from surveys of fibre concentrations in the township conducted periodically by the Health Department of Western Australia, subjects not working directly with asbestos were assigned an intensity of exposure of l fibre/ $\mathrm{ml}(\mathrm{f} / \mathrm{ml})$ from 1943 to 1957 when a new mill was commissioned and the town was moved, and then $0.5 \mathrm{f} / \mathrm{ml}$ between 1958 and 1966 when the mining operation ceased. Since then, interpolation was used to assign exposures between periodic hygiene surveys using personal monitors from $0.5 \mathrm{f} / \mathrm{ml}$ in 1966 to $0.01 \mathrm{f} / \mathrm{ml}$ in 1992. Duration of residence was obtained from a questionnaire either completed at the Vitamin A Program or mailed to the subject. Individual cumulative exposures were calculated by combining the duration of residence and the intensity of exposure for each person.

Estimations of asbestos exposure have been shown to be internally valid on the basis of lung fibre content of surgical and post-mortem specimens and dose-response characteristics for mesothelioma, lung cancer, and asbestosis. ${ }^{73}$

\section{Radiographic assessment for asbestosis}

The plain chest radiograph at each participant's first visit was evaluated by a panel of trained and experienced readers who read it according to the International Labour Office's (ILO) classification of the chest radiographic manifestations of pneumoconiosis, ${ }^{14}$ using the standard films provided by the ILO for side by side comparison. In participants whose radiograph was read by three independent readers, agreement between at least two readers was required to identify a parenchymal abnormality. In cases in which all three readers disagreed on the degree of parenchymal profusion, the median reading was chosen. In participants whose radiograph was read by two readers, the score that they agreed on was selected. When their readings did not coincide, the lower reading was selected. For the purpose of this study, asbestosis was defined as a profusion score of $1 / 0$ or greater, as indicated in the ILO guidelines. ${ }^{14}$ Radiographic asbestosis was included in the analysis as a categorical variable.

\section{Smoking history assessment}

Smoking history was obtained from a questionnaire administered at entry to the Vitamin A Program. Information on smoking status (never smokers, ex-smokers and current smokers) was evaluated as a categorical variable.

\section{Statistical analysis}

To assess the effects of asbestos exposure and tobacco smoking on the levels and rates of decline of lung function, the dependent variables $\left(\mathrm{FEV}_{1}, \mathrm{FVC}\right.$, and $\left.\mathrm{FEV}_{1} / \mathrm{FVC}\right)$ were regressed on time, controlling for sex, age and height. The model included the technician who performed the spirometric test and the spirometer used. Together with the main effects, cross sectional and longitudinal interactions (particularly those involving asbestos and smoking variables) were included in the model.

The data were modelled by a general linear mixed effects model using SAS PROC MIXED. ${ }^{15}$ Random effects models are most appropriate for unbalanced longitudinal data or when the intervals between measurements from each subject are not equally spaced. ${ }^{16}$ The model building process was

Table 2 Number of new participants in the Vitamin A Program per year and total number of measurements taken per year

\begin{tabular}{lcc}
\hline Year & New participants & Measurements taken \\
\hline 1992 & 285 & 285 \\
1993 & 250 & 430 \\
1994 & 90 & 386 \\
1995 & 34 & 317 \\
1996 & 177 & 445 \\
1997 & 258 & 531 \\
1998 & 176 & 876 \\
1999 & 67 & 917 \\
2000 & 42 & 850 \\
2001 & 9 & 785 \\
2002 & 4 & 618 \\
Total & 1392 & 6440 \\
\hline
\end{tabular}

Table 1 Demographic and exposure characteristics of a cohort of asbestos exposed subjects at the time of the first measurement

\begin{tabular}{|c|c|c|c|c|}
\hline & Residents & Workers & Women & Men \\
\hline Participants, n (\%) & $573(41.1)$ & $819(58.9)$ & $363(26.1)$ & $1029(73.9)$ \\
\hline $\mathrm{FEV}_{1}(\mathrm{ml})^{*}$ & 2948 (887) & $2734(714)$ & $2408(601)$ & 2968 (807) \\
\hline FVC $(m l)^{*}$ & $3724(1059)$ & 3604 (859) & $3029(686)$ & $3874(807)$ \\
\hline $\mathrm{FEV}_{1} / \mathrm{FVC}^{*}$ * & $78.9(6.5)$ & $75.7(8.2)$ & $79.2(6.4)$ & $76.3(7.9)$ \\
\hline Age (years)* & $50.7(12.5)$ & $59.2(7.8)$ & $52.8(12.1)$ & $56.8(10.1)$ \\
\hline Height $(\mathrm{cm})^{*}$ & $168(9.5)$ & $171(7.5)$ & $162(6.1)$ & $173(7)$ \\
\hline Cumulative asbestos ( $f / m l$-year)* & $6.9(7.5)$ & $24.7(48)$ & $6.9(7.5)$ & $21.5(44.0)$ \\
\hline Years since last asbestos exposure* & $32.4(8.3)$ & $33.1(5.1)$ & $33.7(7.1)$ & $32.5(6.3)$ \\
\hline Age at first asbestos exposure (years) * & $13.9(12.7)$ & $24.8(6.1)$ & $16.0(12.4)$ & $22.1(9.5)$ \\
\hline Years exposed to asbestos* & $3.0(3.4)$ & $1.1(1.5)$ & $2.9(3.3)$ & $1.4(2.2)$ \\
\hline Radiographic asbestosis, n (\%) & $8(1.4)$ & $144(17.6)$ & $3(0.8)$ & $149(14.5)$ \\
\hline Current smokers, $\mathrm{n}(\%)$ & $111(19.6)$ & $175(21.8)$ & $68(19.3)$ & $218(21.5)$ \\
\hline Ex-smokers, $n(\%)$ & $181(31.5)$ & $446(54.2)$ & $86(23.6)$ & $541(52.5)$ \\
\hline Never smokers, $\mathrm{n}(\%)$ & $280(48.9)$ & $196(23.9)$ & $208(56.9)$ & $268(26.0)$ \\
\hline
\end{tabular}


Table 3 Mean (SD) characteristics of the follow up of asbestos exposed subjects

\begin{tabular}{|c|c|c|c|c|}
\hline & Residents & Workers & Women & Men \\
\hline Total determinations of lung function & 2240 (34.7) & $4200(65.2)$ & $1466(22.7)$ & $4974(77.2)$ \\
\hline Determinations of lung function per person & $3.9(1.7)$ & $5.1(2.8)$ & $4.0(2.0)$ & $4.8(2.6)$ \\
\hline Follow up (years) & $3.3(1.8)$ & $5.7(3.5)$ & $3.7(2.3)$ & $5.1(3.3)$ \\
\hline Months between determinations & $13.7(4.8)$ & $16.5(10.1)$ & $14.6(6.8)$ & $15.8(9.2)$ \\
\hline
\end{tabular}

performed following the steps suggested by Diggle $e t a l^{17}$ and Verbeke and Molenberghs. ${ }^{16}$ Initially a model with all the explanatory variables and their biologically plausible interactions was applied in order to remove any systematic trends. In the second step random effects were included in the model; the best model was selected according to a likelihood ratio test. Thirdly, several residual covariance structures were tested and the best was selected according to the Akaike Information Criterion (AIC). Finally, the model was simplified by deleting non-significant terms. Estimation was made by the restricted maximum likelihood method and tests were performed using the $5 \%$ level of significance. Model validation was carried out by checking normal distribution of residuals. Outliers were identified and their model based effects assessed.

The analyses were performed separately for residents and workers; however, as this stratified analysis produced similar relationships between lung function and asbestos and smoking exposure to statistical adjustment, only models using the statistical adjustment are presented.

\section{RESULTS}

A total of 6440 determinations from 1392 participants with at least one spirometric test were analysed. The demographic characteristics and exposure histories at the first visit showed that former workers had lower levels of $\mathrm{FEV}_{1}, \mathrm{FVC}$, and $\mathrm{FEV}_{1} /$ FVC than ex-residents (table 1). Workers were exposed to higher cumulative amounts of asbestos (median $6.40 \mathrm{f} / \mathrm{ml}$ per year, interquartile range 1.92-26.01) and included a higher proportion with radiographic asbestosis. Although ex-residents were exposed to asbestos for longer periods of time, their cumulative asbestos exposure was lower as the intensity of exposure was much higher in the mining and milling processes. Ex-residents tended to be exposed to asbestos at a younger age than workers. In addition, workers included a higher proportion of ever smokers. Women were less exposed to asbestos and smoked less than men. 272 ex-residents were men, and 62 women were workers; 757 subjects were male workers.
The number of people recruited and the number of spirometric measurements varied over the years (table 2); $14 \%$ of participants had one measurement, $11 \%$ had two measurements, $11 \%$ had three, $12 \%$ had four, $16 \%$ had five, $14 \%$ had six, and $22 \%$ had more than six measurements during the period of observation. The Vitamin A Program initially gave preference to enrolling workers, who were mostly men, because of their greater risks of developing asbestos related diseases. They therefore had more spirometric measurements per person and a longer follow up time (table 3).

A plot of individual profiles suggested modelling $\mathrm{FEV}_{1}$, $\mathrm{FVC}$, and $\mathrm{FEV}_{\mathrm{l}} / \mathrm{FVC}$ as linear functions over time. The likelihood ratio test showed a significant difference favouring the random-intercept plus random-slope model. The simple covariance structure and the compound symmetry covariance structure produced the smallest AIC values, so the compound symmetry covariance structure was applied to describe the fixed effects in the present report.

According to the regression model, the typical levels of lung function were $2761 \mathrm{ml}$ for $\mathrm{FEV}_{1}, 3532 \mathrm{ml}$ for $\mathrm{FVC}$, and $77.6 \%$ for $\mathrm{FEV}_{\mathrm{l}} / \mathrm{FVC}$ (table 4 ). These values correspond to never smoking male workers with a cumulative asbestos exposure of $20 \mathrm{f} / \mathrm{ml}$-year and no radiographic asbestosis, having an entry age of 56 years and a height of $165 \mathrm{~cm}$. On average, $\mathrm{FEV}_{1}$ declined by $24 \mathrm{ml}$ per year (95\% CI 20 to 28) while FVC declined by $39 \mathrm{ml}$ per year (95\% CI 35 to 45 ) and $\mathrm{FEV}_{\mathrm{l}} / \mathrm{FVC}$ had a small but significant increment of $0.17 \%$ per year (95\% CI 0.07 to 0.27 ) (table 5 ).

Controlling for potential confounders, ex-residents had higher levels of $\mathrm{FEV}_{1}(157 \mathrm{ml}), \mathrm{FVC}(110 \mathrm{ml})$, and $\mathrm{FEV}_{\mathrm{l}} / \mathrm{FVC}$ $(1.2 \%)$ than workers (table 4$)$. There were no significant differences between ex-workers and ex-residents in the annual changes in $\mathrm{FEV}_{1}, \mathrm{FVC}$, or $\mathrm{FEV}_{1} / \mathrm{FVC}$ (table 5).

Each additional f/ml-year of asbestos exposure was associated with a decrease in the level of $\mathrm{FEV}_{1}$ of $0.9 \mathrm{ml}$ (95\% CI 0.31 to 1.50 ) and in FVC of $1.5 \mathrm{ml} \mathrm{(95 \%} \mathrm{CI} 0.72$ to 2.29). People with higher levels of exposure to asbestos had greater declines in $\mathrm{FEV}_{1}$ and FVC over time. Similarly,

Table 4 Predictors of level of lung function in a cohort of asbestos exposed subjects according to the linear mixed model

\begin{tabular}{|c|c|c|c|c|c|c|}
\hline & \multicolumn{2}{|l|}{$\mathrm{FEV}_{\mathbf{l}}(\mathrm{ml})$} & \multicolumn{2}{|l|}{ FVC (ml) } & \multicolumn{2}{|l|}{$\mathrm{FEV}_{1} / \mathrm{FVC} \%$} \\
\hline & Estimate (SE) & p value & Estimate (SE) & p value & Estimate (SE) & $\mathrm{p}$ value \\
\hline Intercept & $2761(66)$ & $<0.001$ & $3532(74)$ & $<0.001$ & $77.6(0.5)$ & $<0.001$ \\
\hline Age at entry (years) & $-41(2)$ & $<0.001$ & $-44(2)$ & $<0.001$ & $-0.21(0.02)$ & $<0.001$ \\
\hline Female & $-490(44)$ & $<0.001$ & $-594(49)$ & $<0.001$ & & \\
\hline Height $(\mathrm{cm})$ & $34(2)$ & $<0.001$ & $49(2)$ & $<0.001$ & $-0.11(0.02)$ & $<0.001$ \\
\hline Ex-resident & $157(37)$ & $<0.001$ & $110(41)$ & 0.001 & $1.23(0.48)$ & 0.01 \\
\hline $\begin{array}{l}\text { Cumulative asbestos exposure } \\
\text { (f/ml-year) }\end{array}$ & $-0.9(0.3)$ & 0.001 & $-1.5(0.4)$ & $<0.001$ & $0.006(0.005)$ & 0.19 \\
\hline Radiographic asbestosis & $-313(46)$ & $<0.001$ & $-381(52)$ & $<0.001$ & $-0.70(0.65)$ & 0.28 \\
\hline $\begin{array}{l}\text { Age first asbestos exposure } \\
\text { (years) }\end{array}$ & $6.2(2.4)$ & 0.01 & $8.7(2.7)$ & 0.00 & & \\
\hline Current smokers & $-350(38)$ & $<0.001$ & $-283(42)$ & $<0.001$ & $-4.10(0.55)$ & $<0.001$ \\
\hline Ex-smokers & $-39(32)$ & 0.22 & $-1.0(36)$ & 0.98 & $-1.15(0.46)$ & 0.01 \\
\hline
\end{tabular}

All variables were included in the model. Age was centred to 56 years and height to $165 \mathrm{~cm}$. In order to get a more precise estimate of the lung function levels, the model also included the operator who performed the spirometric tests and the spirometer used, although the effects of these variables on lung function were not substantial. 
Table 5 Predictors of change of lung function in a cohort of asbestos exposed subjects according to the linear mixed model

\begin{tabular}{|c|c|c|c|c|c|c|}
\hline & \multicolumn{2}{|l|}{$\mathrm{FEV}_{1}(\mathrm{ml})$} & \multicolumn{2}{|l|}{ FVC (ml) } & \multicolumn{2}{|l|}{$\mathrm{FEV}_{1} / \mathrm{FVC} \%$} \\
\hline & Estimate (SE) & $p$ value & Estimate (SE) & $p$ value & Estimate (SE) & $p$ value \\
\hline $\begin{array}{l}\text { Follow up (years) } \\
\text { Follow up* cumulative asbestos } \\
\text { Follow up* radiographic asbestosis } \\
\text { Follow up* current smokers } \\
\text { Follow up* ex-smokers }\end{array}$ & $\begin{array}{l}-24(2) \\
-0.08(0.02) \\
-13(2) \\
-13(2) \\
-1.0(2.0)\end{array}$ & $\begin{array}{l}<0.001 \\
0.001 \\
<0.001 \\
<0.001 \\
0.62\end{array}$ & $\begin{array}{l}-39(3) \\
-0.10(0.03) \\
-20(3) \\
-3.3(3.3) \\
3.8(2.5)\end{array}$ & $\begin{array}{l}<0.001 \\
0.001 \\
<0.001 \\
0.31 \\
0.13\end{array}$ & $\begin{array}{l}0.17(0.05) \\
-0.41(0.05) \\
-0.13(0.04)\end{array}$ & $\begin{array}{l}0.001 \\
<0.001 \\
0.001\end{array}$ \\
\hline
\end{tabular}

cumulative asbestos exposure tended to be associated with an increase in $\mathrm{FEV}_{1} / \mathrm{FVC}$, but it was not a significant predictor of change in $\mathrm{FEV}_{\mathrm{l}} / \mathrm{FVC}$ over time.

Subjects with radiographic asbestosis had lower $\mathrm{FEV}_{1}$ $(313 \mathrm{ml})$ and FVC $(381 \mathrm{ml})$ levels than those without asbestosis (table 4). The presence of asbestosis was associated with an additional decrease of $13 \mathrm{ml} /$ year (95\% CI 9 to 17) in $\mathrm{FEV}_{1}$ and of $20 \mathrm{ml}(95 \% \mathrm{CI} 14$ to 26$)$ in $\mathrm{FVC}$, but it was not associated with the level or the rate of decline of $\mathrm{FEV}_{1} / \mathrm{FVC}$ (table 5).

Age at first exposure to asbestos was a significant predictor of the levels of $\mathrm{FEV}_{1}$ and FVC, indicating that people exposed to asbestos at a younger age had lower levels of $\mathrm{FEV}_{1}$ and FVC (table 4). Years since last exposure to asbestos was not a significant predictor of lung function in this population.

Current smokers had significantly lower levels of $\mathrm{FEV}_{1}$, $\mathrm{FVC}$, and $\mathrm{FEV}_{1} / \mathrm{FVC}$ than never smokers. $\mathrm{FEV}_{1}$ and FVC levels in ex-smokers were similar to never smokers, but their $\mathrm{FEV}_{1} /$ FVC was significantly lower (table 4). Compared with never smokers, the rate of decline of $\mathrm{FEV}_{1}$ was steeper in current smokers and was not significantly different in ex-smokers; $\mathrm{FEV}_{\mathrm{l}} / \mathrm{FVC}$ decreased faster in both current smokers and exsmokers than in never smokers (table 5).

No significant statistical interactions between asbestos exposure and smoking history on levels or rate of decline of lung function were observed in this population.

The relationships between asbestos exposure and tobacco with lung function did not change when the drug being taken at the time of the measurement ( $\beta$-carotene or retinol) was included in the model.

\section{DISCUSSION}

This study shows that subjects with higher cumulative doses of crocidolite or with radiographic asbestosis had significantly lower levels of $\mathrm{FEV}_{1}$ and FVC and a steeper decline during the follow up period. Subjects exposed to asbestos at a younger age had lower levels of $\mathrm{FEV}_{1}$ and FVC. FEV $/ \mathrm{FVC}$ was not associated with radiographic asbestosis, and subjects with asbestosis had no change in the ratio of $\mathrm{FEV}_{1} / \mathrm{FVC}$ measurements. This finding is consistent with the development of a restrictive ventilatory defect in asbestosis even though, in the earliest histological grade of asbestosis, fibrosis involves the respiratory bronchioles. ${ }^{18}$

Several previous studies have shown that asbestos exposure negatively affects both the levels and rate of change of lung function. ${ }^{219} 20$ However, most of the previous studies evaluating the effect of asbestos exposure on lung function have been in cohorts exposed to mixed asbestos fibres, while the Wittenoom cohort is unique in that they were exposed exclusively to crocidolite. Studies in animals and humans have indicated that crocidolite fibres are more persistent and biologically more active, tend to cause asbestos related diseases (particularly mesothelioma) at lower exposure loads, and tend to produce a more rapid progression of these diseases. ${ }^{21}{ }^{22}$ Although it would be biologically plausible to propose that the damage in lung function is greater in those exposed to crocidolite than those exposed to other types of asbestos fibres, different occupational conditions and varying methodological approaches make difficult a direct comparison of the estimated effects.

Cross sectional studies have typically shown that measures of lung function are highest in never smokers, lowest in sustained smokers, and intermediate in those who have stopped smoking. ${ }^{23}{ }^{24}$ Longitudinally, it has been shown that active smoking accelerates the rate of decline of lung function and, on average, smokers experience 10-20 ml/year more $\mathrm{FEV}_{1}$ loss than never smokers, although a subgroup of "susceptible smokers" may experience declines that can be more than three times higher than in never smokers. ${ }^{23-25}$ Results from the present analysis are consistent with these findings. The levels and rate of decline of $\mathrm{FEV}_{1}$ in ex-smokers returns towards that experienced by never smokers (after accounting for the effects of crocidolite on lung function), which is in agreement with the reported beneficial effect of smoking cessation. ${ }^{26}$ However, $\mathrm{FEV}_{\mathrm{l}} / \mathrm{FVC}$ continued to decline in ex-smokers during the follow up period, increasing the obstructive pattern associated with tobacco smoking.

Previous reports have suggested that cigarette smoking enhances the development of interstitial fibrosis in workers exposed to asbestos. ${ }^{4}$ The finding of interactions between tobacco smoking and asbestos exposure on lung function may be associated with the peribronchial fibrosis and the bronchial wall thickening ("dirty lungs") produced by smoking. ${ }^{27}$ Although in preliminary analysis a significant interaction of smoking status on the relationship between asbestos exposure and lung function was found $(\mathrm{p}=0.03$ in $\mathrm{FEV}_{1}, \mathrm{p}=0.003$ in FVC), statistical significance was not observed after adjusting for potential confounders in the mixed effects model. Our findings suggest that smoking and asbestos exposure were acting independently (additively) rather than synergistically (multiplicatively) on the level and rate of decline in lung function in this population. The discrepancy of these findings compared with previous results ${ }^{45}$ may be explained by the study of varying occupational conditions and different analytical methods.

The present study has the advantage of having both cross sectional and longitudinal components in the analysis of the data, which make efficient use of all the available information and explores hypotheses unable to be tested with cross sectional approaches alone. The accurate evaluation of tobacco smoke exposure in this report, as in most others, has some limitations because it was based on self-reporting. This report analyses the smoking status at the beginning of the follow up period and does not include the analysis of changes in smoking habits over time, as this information was not systematically collected during the study.

As extracting asbestos involves drilling and blasting, processes that are often dusty, exposure to other mineral dusts, particularly silica, is an additional hazard of asbestos mining that is experienced in certain mines including Wittenoom. ${ }^{6}{ }^{28}$ These exposures were not assessed in this study so we were not able to account for their potential confounding effect. In addition, confounder factors from the diet were not accounted for in this study. We report estimates 
for the effect of smoking using categories (never, current and ex-smokers) which raises the possibility of residual confounding by smoking. However, the addition of other smoking variables in the model (number of cigarettes per day, duration of smoking) did not substantially alter the estimates of the effects of asbestos on lung function.

Due to self-selection into the Vitamin A Program, this population may not be representative of the whole cohort exposed to crocidolite at Wittenoom. People who participated in the Program were more likely to be younger and more exposed to cumulative asbestos exposure. The result from this study may not apply to lower exposure levels and older age groups.

A major analytical problem in longitudinal studies is the frequent occurrence of missing data-particularly missing data due to withdrawals - which may be associated with systematic error or bias. ${ }^{29}$ Ninety subjects $(6.3 \%)$ dropped out of the study; 142 participants who died during the follow up period were not counted as dropouts as they had complete collected information. ${ }^{16}$ People who abandoned the Program had lower levels of $\mathrm{FEV}_{1}, \mathrm{FVC}$, and $\mathrm{FEV}_{1} / \mathrm{FVC}$ than those who remained in the Program. Following Littell and Rubin's terminology for classifying mechanisms of missing data, ${ }^{30}$ we have assumed a "missing at random pattern" which means that any withdrawal from the study did not depend on the lung function itself, although it may depend on some covariates. With a "missing at random pattern", methods based on likelihood will produce valid inferences if the model specification is correct. Applying an available case analysis using PROC MIXED of SAS, the reported relationships may be interpreted as the response conditional on the subject remaining in the study. ${ }^{16}$

The results of study show that the deleterious effects of crocidolite exposure on lung function persist in this population, despite exposure having ceased more than 30 years ago. They also confirm the detrimental effect of smoking on lung function and the beneficial effects of smoking cessation. No significant interactions between exposure to asbestos and smoking at the first visit or longitudinally were found in this population.

\section{ACKNOWLEDGEMENTS}

The authors thank the participants of the Program and the Asbestos Diseases Society of Western Australia for their ongoing support; Lynne Watts, Meralyn Pearce, Diane Jacoby and Naomi Hammond for data collection; and Philip Etherington for database management.

\section{Authors' affiliations}

H S Alfonso, L Fritschi, N H de Klerk, N Olsen, J Sleith, A W Musk, School of Population Health, University of Western Australia, Perth, Western Australia, Australia

A W Musk, Department of Respiratory Medicine, Sir Charles Gairdner Hospital, Perth, Western Australia, Australia

N H de Klerk, Department of Biostatistics and Genetic Epidemiology, Telethon Institute for Child Health Research, Perth, Western Australia, Australia

The cancer preventive program was funded by the Western Australia Department of Health and the Worker's Compensation and Rehabilitation Commission of Western Australia. The follow up of the Wittenoom cohort was supported by the National Health and Medical Research Council (NHMRC) of Australia.

\section{REFERENCES}

1 Rom WN, Travis WD, Brody AR. Cellular and molecular basis of the asbestosrelated diseases. Am Rev Respir Dis 1991;143:408-22.

2 Rom WN. Accelerated loss of lung function and alveolitis in a longitudinal study of non-smoking individuals with occupational exposure to asbestos. Am J Ind Med 1992;21:835-44.

3 Nakadate T. Decline in annual lung function in workers exposed to asbestos with and without pre-existing fibrotic changes on chest radiography. Occup Environ Med 1995;52:368-73.

4 Lilis R, Selikoff IJ, Lerman Y, et al. Asbestosis: interstitial pulmonary fibrosis and pleural fibrosis in a cohort of asbestos insulation workers: influence of cigarette smoking. Am J Ind Med 1986;10:459-70.

5 Miller A, Lilis R, Godbold J, et al. Spirometric impairments in long-term insulators. Relationships to duration of exposure, smoking, and radiographic abnormalities. Chest 1994;105:175-82.

6 Musk AW, de Klerk NH, Eccles JL, et al. Wittenoom, Western Australia: a modern industrial disaster. Am J Ind Med 1992;21:735-47.

7 Armstrong BK, de Klerk NH, Musk AW, et al. Mortality in miners and millers of crocidolite in Western Australia. Br J Ind Med 1988;45:5-13.

8 Hansen J, de Klerk NH, Eccles JL, et al. Malignant mesothelioma after environmental exposure to blue asbestos. Int J Cancer 1993;54:578-81.

9 Musk AW, de Klerk NH, Ambrosini NH, et al. Vitamin A and cancer prevention I: Observations in workers previously exposed to asbestos at Wittenoom, Western Australia. Int J Cancer 1998;75:355-61.

10 de Klerk NH, Musk AW, Ambrosini GL, et al. Vitamin A and cancer prevention II: Comparison of the effects of retinol and beta-carotene. Int J Cancer 1998;75:362-7.

11 Quanjer PH, Tammeling GJ, Cotes JE, et al. Lung volumes and forced ventilatory flows. Report Working Party Standardization of Lung Function Tests, European Community for Steel and Coal. Official Statement of the European Respiratory Society. Eur Respir J 1993; 16:5-40.

12 American Thoracic Society, Standardization of spirometry: 1987 update. Statement of the American Thoracic Society. Am Rev Respir Dis 1987; 136:1285-98.

13 Hansen J, de Klerk NH, Musk AW, et al. Environmental exposure to crocidolite and mesothelioma: exposure-response relationships. Am J Respir Crit Care Med 1998; 157:69-75.

14 International Labour Organization (ILO). International classification of radiographs of pneumoconiosis. Guidelines for the use. Geneva: International Labor Office, 1980.

15 SAS/STAT. User's guide. Version 8.2. Cary, NC: SAS Institute Inc, 1999.

16 Verbeke G, Molenberghs G. Linear mixed models for longitudinal analysis. New York: Springer-Verlag, 2000

17 Diggle PJ, Liang KY, Zeger SL. Analysis of longitudinal data. New York: Oxford University Press, 1994.

18 Gibbs AR, Seal RM. Occupational lungs disorders II. Silicate pneumoconiosis. In, Atlas of pulmonary pathology Lancaster, MTP Press, 1982:91.

19 Glencross PM, Weinberg JM, Ibrahim JG, et al. Loss of lung function among sheet metal workers: ten-year study. Am J Ind Med 1997;32:460-6.

20 Jones RN, Diem JE, Hughes JM, et al. Progression of asbestos effects: a prospective longitudinal study of chest radiographs and lung function. $\mathrm{Br} J$ Ind Med 1989;46:97-105.

21 Hodgson JT, Darnton A. The quantitative risks of mesothelioma and lung cancer in relation to asbestos exposure. Ann Occup Hyg 2000;44:565-601.

22 Cookson WO, de Klerk NH, Musk AW, et al. The natural history of asbestosis in former crocidolite workers of Wittenoom Gorge. Am Rev Respir Dis 1986; 133:994-8.

23 Anthonisen NR, Connett JE, Kiley JP, et al. Effects of smoking intervention and the use of an inhaled anticholinergic bronchodilator on the rate of decline of $\mathrm{FEV}_{1}$. The Lung Health Study. JAMA 1994;272:1497-505.

24 Fletcher C, Peto R, Tinker C, et al. The natural history of chronic bronchitis and emphysema. New York: Oxford University Press, 1976.

25 Xu X, Dockery DW, Ware JH, et al. Effects of cigarette smoking on rate of loss of pulmonary function in adults: a longitudinal assessment. Am Rev Respir Dis 1992;146:1345-8.

26 Samet JM, Lange P. Longitudinal studies of active and passive smoking Am J Respir Crit Care Med 1996;154:S257-65.

27 Cotes JE. Lung function. In: Assessment and aplication in medicine. 4th ed. Oxford: Blackwell Scientific Publications, 1993.

28 Hills B. Blue Murder: two thousand doomed to die: the shocking truth about Wittenoom's deadly dust. Melbourne: Sun Macmillan, 1989.

29 Touloumi G, Pocock SJ, Babiker AG, et al. Estimation and comparison of rates of change in longitudinal studies with informative drop-outs. Stat Med 1999;18:1215-33.

30 Littell RC, Rubin DB. Statistical analysis with missing data. New York: John Wiley, 1987. 